http://jmscr.igmpublication.org/home/ ISSN (e)-2347-176x ISSN (p) 2455-0450

crossref DOI: https://dx.doi.org/10.18535/jmscr/v7i11.06

Journal Of Medical Science And Clinical Research

\title{
Study of clinical profile of patients intubated and those on non invasive ventilation in Emergency Medicine Department
}

\author{
Authors \\ Sumalya Tripathi ${ }^{1}$, Varsha Shinde ${ }^{2}$, Zahid Shaikh ${ }^{3}$ \\ Department of Emergency Medicine, DY Patil Medical College and Research Centre, \\ DY Patil Vidyapeeth University, Pune-411018 \\ *Corresponding Author \\ Dr Varsha Shinde \\ Department of Emergency Medicine, Dr DY Patil Medical College, DY Patil Vidyapeeth University, \\ Pune-411018, India
}

\begin{abstract}
Background: An unobstructed, protected airway and adequate ventilation are critical to prevent hypoxemia. Emergency medicine is an emerging branch in India at present and no research has been conducted to evaluate baseline demographic features, indications, modes of ventilation etc for patients requiring mechanical ventilation in $E D$.

Methods: All patients requiring mechanical ventilation with age $>12$ years, not treated outside and admitted to emergency medicine department from July 2017 to September 2019 were included in our study. Data collected for each patient included age, sex, vitals on presentation i.e. temperature, pulse, BP, $S p O 2, R R, G C S$, systemic examination, diagnosis, mode of mechanical ventilation and $A B G$.

Results: $57 \%$ subjects were ventilated by invasive, $33 \%$ by non invasive ventilation and $10 \%$ by both mode of ventilation. Mean age of study subjects was $57.37 \pm 16.42 .67 \%$ of the patients were males and $33 \%$ were females. Most common diagnosis was COPD exacerbation. Of patients who were invasively ventilated, $63 \%$ were on volume assist mode and $4 \%$ on pressure control mode. Out of 33 patients kept on NIV, 11 patients were on CPAP mode and rest 22 on PSV+CPAP mode. $42 \%$ patients had respiratory acidosis and $29 \%$ had metabolic acidosis. The subjects with lower GCS, low SpO2 and raised RR on presentation required invasive mode. Among NIV and intubation group Systolic BP, Diastolic BP and Respiratory rate showed significant difference in mean values $(p<0.05)$.

Conclusion: This study provided information about recent epidemiological trends in our ED and may help derive a management protocol for better outcome of patients in future.
\end{abstract}

\section{Introduction}

Airway management is a critical need in many acutely ill and injured patients Inadequate delivery of oxygen to brain and other vital structures is the quickest killer. An unobstructed, protected airway and adequate ventilation are critical to prevent hypoxemia.
Emergency airway management is the major key for successful resuscitation in ED. Emergency department deals with most of the cases with threatened airway and impending respiratory failure requiring mechanical ventilation. This early period of care has significant impact on the outcomes of these patients. Emergency medicine is an emerging 
branch in India at present and no research study has been conducted to evaluate baseline demographic features, indications, difficult airway assessment, modes of ventilation etc for patients requiring mechanical ventilation in the ED setting.

Therefore by this observational study we try to study the baseline characteristics of patients requiring mechanical ventilation in ED settings.

\section{Aim}

To study the clinical profile of patients intubated and those on NIV in Emergency Department.

\section{Objectives}

1. To study various indications of need for mechanical ventilation.

2. To study the demographic features of patients on mechanical ventilation.

3. To assess how many patients can be managed with non invasive ventilation versus invasive ventilation in EM.

4. To tabulate different ventilator settings used.

\section{Methodology}

\section{Study Design}

Prospective observational study.

\section{Place of Study}

The present study was done on the patients in the Department of Emergency Medicine at Dr. D.Y. Patil Medical College, Hospital and Research Centre, Pimpri, Pune.

\section{Study Duration}

July 2017 to September 2019.

Study was scheduled as:

1. Preparatory phase: 1 month ( synopsis submission for ethical clearance)

2. Case screening, recruitment and data collection: 16 months

3. Data analysis and writing : 3 months

\section{Sample Size and Sampling Technique}

The sample size was estimated based on single population proportion formula using a confidence interval (CI) of $95 \%$ and a $40 \%$ invasive ventilation of previous study by Mohamed A. Zamzama, Amal A. Abd El Aziza, et al. ${ }^{[2]}$ and acceptable difference of $10 \%$ using sample size formula was 95.

Where, $\mathrm{n}=$ sample size,

$$
\mathrm{N}=\mathrm{z}^{2} \mathrm{pq} / \mathrm{d}^{2}
$$

$\mathrm{Z}=1.96$

$\mathrm{p}=$ proportion of invasive ventilation

$\mathrm{d}=$ assumed marginal error.

Total 100 subjects were included in study. Participants were selected using convenience sampling technique.

\section{Data Analysis}

Data was entered into computer Microsoft Excel and exported to SPSS version 20 for analysis.

Continuous variables were expressed as mean \pm standard deviation or median (range) and categorical variables were expressed as number (percentage).

For categorical variable association between exposure and outcome variable was analysed using Chi square or Fisher exact test. P value $<0.05$ was considered statistically significant.

\section{Ethical Clearance}

Study was conducted only after the clearance from ethical and scientific committee of this institution.

\section{Inclusion Criteria}

All the patients undergoing intubation and noninvasive ventilation in the emergency department during the period of study with age more than 12 years.

\section{Exclusion Criteria}

1. Age less than 12 years.

2. Pregnant

3. Presented to EM who had already taken treatment outside and intubated in the hospital where he / she was admitted previously.

Data Collection: Data collected for each patient includes age, sex, vitals on presentation i.e. temperature, pulse, $\mathrm{BP}, \mathrm{SpO} 2$, RR, GCS, systemic examination, diagnosis, mode of mechanical ventilation, and $\mathrm{ABG}$. 


\section{Observations and Results}

A cross-sectional observational study was conducted with 100 patients to Study the Clinical Profile of Patients Intubated and Those on NonInvasive Ventilation in Emergency Medicine Department.

Distribution of invasive versus non-invasive ventilation:

$57 \%$ subjects were ventilated by invasive, $33 \%$ by non invasive ventilation and $10 \%$ by both mode of ventilation (NIV followed by invasive ventilation)

Table 1 : Mode of Ventilation

\begin{tabular}{lcc}
\hline Mode of ventilation & Frequency & Percentage \\
\hline NIV & 33 & $33.00 \%$ \\
Intubation & 57 & $57.00 \%$ \\
both & 10 & $10.00 \%$ \\
\hline Total & 100 & $100.00 \%$ \\
\hline
\end{tabular}

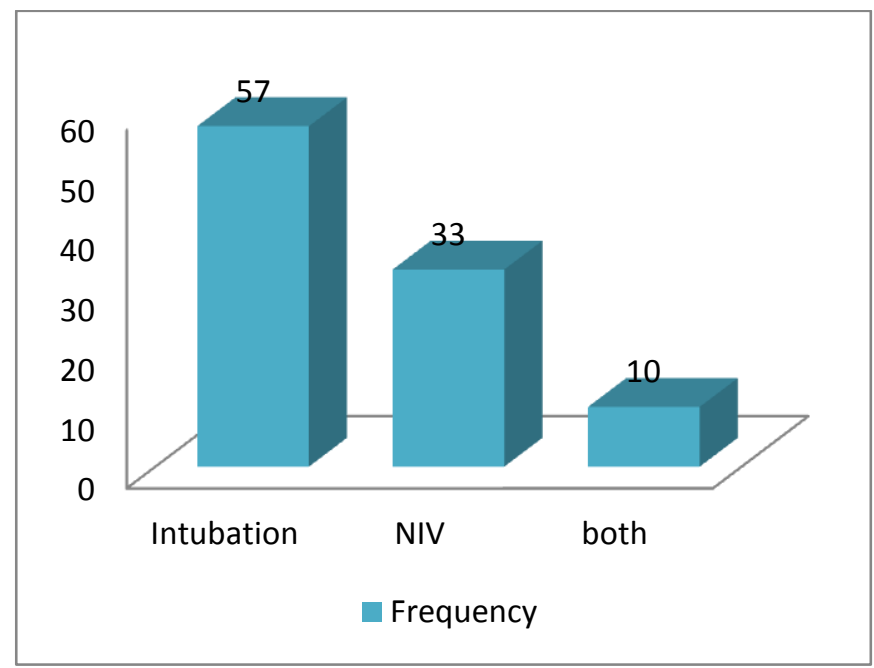

Figure 1: Mode of ventilation

\section{Distribution of patients according to AGE}

Maximum $31 \%$ subjects were in age group of 61 $70 y$ rs followed by $21 \%$ subjects in $51-60 y$ rs $13 \%$ subjects in $41-50 \mathrm{yrs}$ and $12 \%$ subjects in $71-80 \mathrm{yrs}$. Mean age of study subjects was $57.37+16.42$ and total subjects were in age range of $16-87 \mathrm{yrs}$.

Table 2: Age wise distribution of study subjects

\begin{tabular}{lcc}
\hline Age group & Frequency & Percent \\
\hline$<30 y r s$ & 7 & $7.00 \%$ \\
31-40ys & 10 & $10.00 \%$ \\
$41-50 y r s$ & 13 & $13.00 \%$ \\
$51-60 y r s$ & 21 & $21.00 \%$ \\
$61-70 y r s$ & 31 & $31.00 \%$ \\
$71-80 y r s$ & 12 & $12.00 \%$ \\
$>80 y r s$ & 6 & $6.00 \%$ \\
Total & 100 & $100.00 \%$ \\
\hline
\end{tabular}

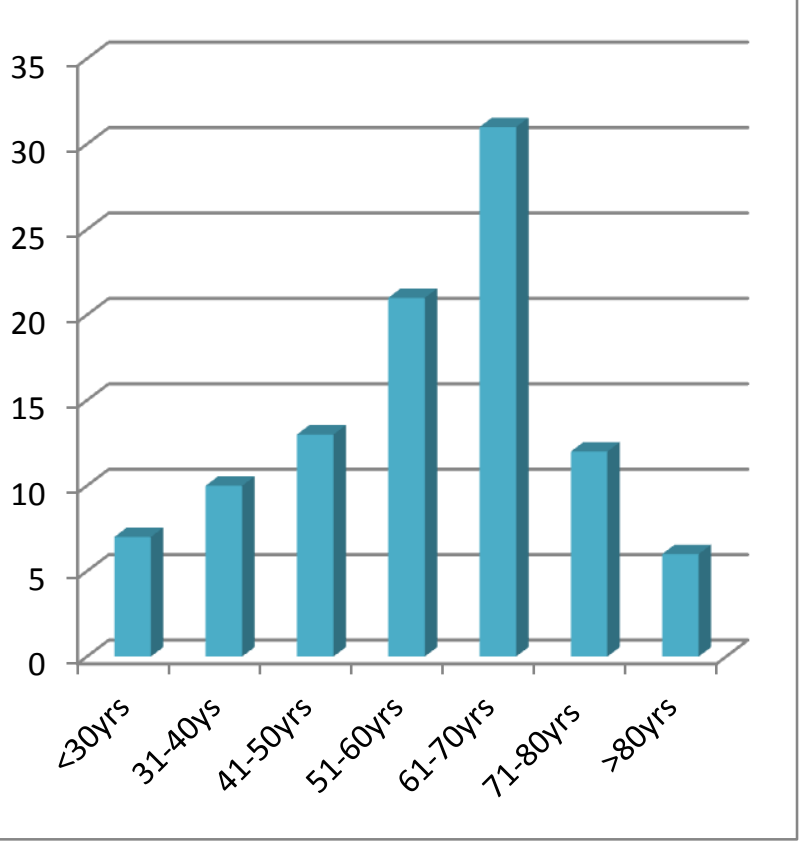

Figure 2: Age wise distribution of study subjects

Type of ventilation required among age groups:

In our study it was found that there was increased requirement of intubation with increase in age. (Patients that were put on NIV as well as intubated were excluded from the following table)

Table 3: Type of ventilation required among Age group

\begin{tabular}{lccc}
\hline & \multicolumn{3}{c}{ Ventilation } \\
\cline { 2 - 4 } Age group & NIV & Intubation & Total \\
<30yrs & $3(50.00 \%)$ & $3(50.00 \%)$ & 6 \\
31-40yrs & $2(20.00 \%)$ & $8(80.00 \%)$ & 10 \\
$41-50 y r s$ & $6(46.15 \%)$ & $7(53.85 \%)$ & 13 \\
$51-60 y r s$ & $7(35.00 \%)$ & $13(65.00 \%)$ & 20 \\
61-70yrs & $13(46.43 \%)$ & $15(53.57 \%)$ & 28 \\
$71-80 y r s$ & $2(25.00 \%)$ & $6(75.00 \%)$ & 8 \\
$>80 y r s$ & 0 & $5(100.00 \%)$ & 5 \\
Total & $33(36.67 \%)$ & $57(63.33 \%)$ & 90 \\
\hline \multicolumn{4}{c}{} \\
\hline
\end{tabular}

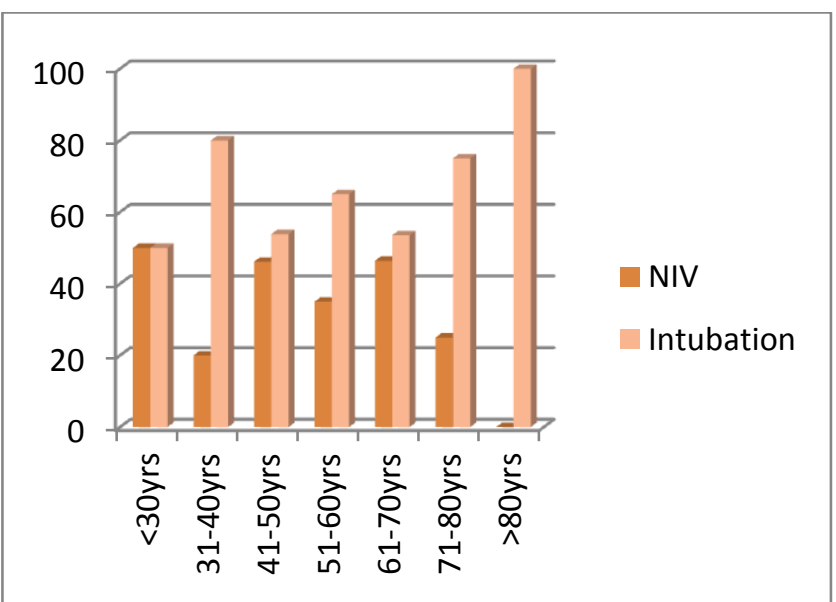

Figure 3: Type of ventilation required among age group 


\section{Distribution of patients according to gender}

$67 \%$ of the patients in our study were males, while female patients constituted $33 \%$ of the study population. Gender wise distribution in our study was $\mathrm{M}: \mathrm{F}=2.03: 1$

Table 4 : Gender wise distribution of study subjects

\begin{tabular}{lcc}
\hline Gender & Frequency & Percent \\
\hline Female & 33 & $33.00 \%$ \\
Male & 67 & $67.00 \%$ \\
Total & 100 & $100.00 \%$ \\
\hline
\end{tabular}

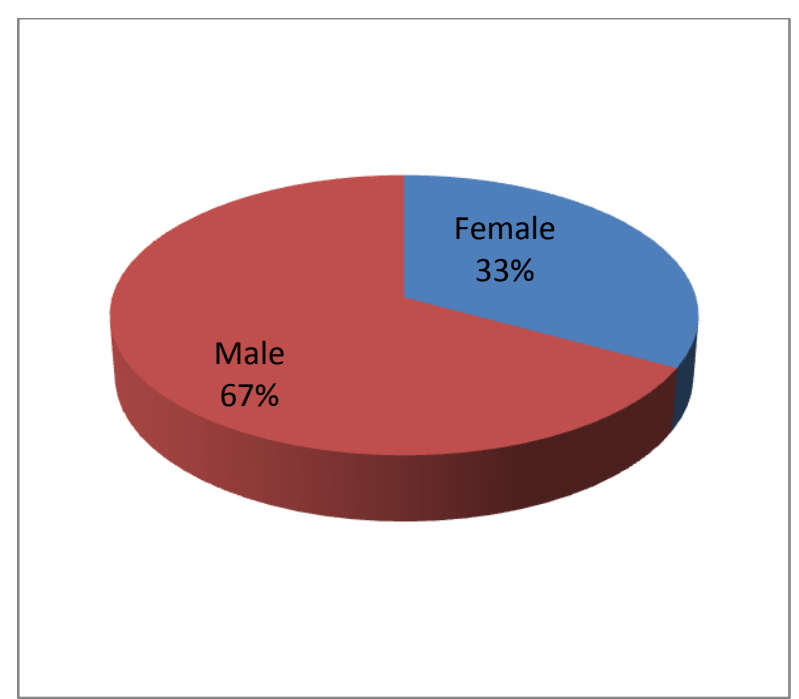

Figure 4: Gender wise distribution of study subjects

Type of ventilation required among male and female:

It was observed that there was no significant difference in non invasive or invasive mode of ventilation required for male and female subjects $(p=0.951) .10$ subjects who required both invasive and non invasive mode of mechanical ventilation were excluded from the following table.

Table 5: Type of ventilation required among male and female study subjects

\begin{tabular}{lccc}
\hline & \multicolumn{2}{c}{ Ventilation } & \\
\cline { 2 - 3 } Gender & NIV & Intubation & Total \\
Female & $11(35.48 \%)$ & $20(64.52 \%)$ & 31 \\
Male & $22(37.29 \%)$ & $37(62.71 \%)$ & 59 \\
Total & $33(36.67 \%)$ & $57(63.33 \%)$ & 90 \\
\hline
\end{tabular}

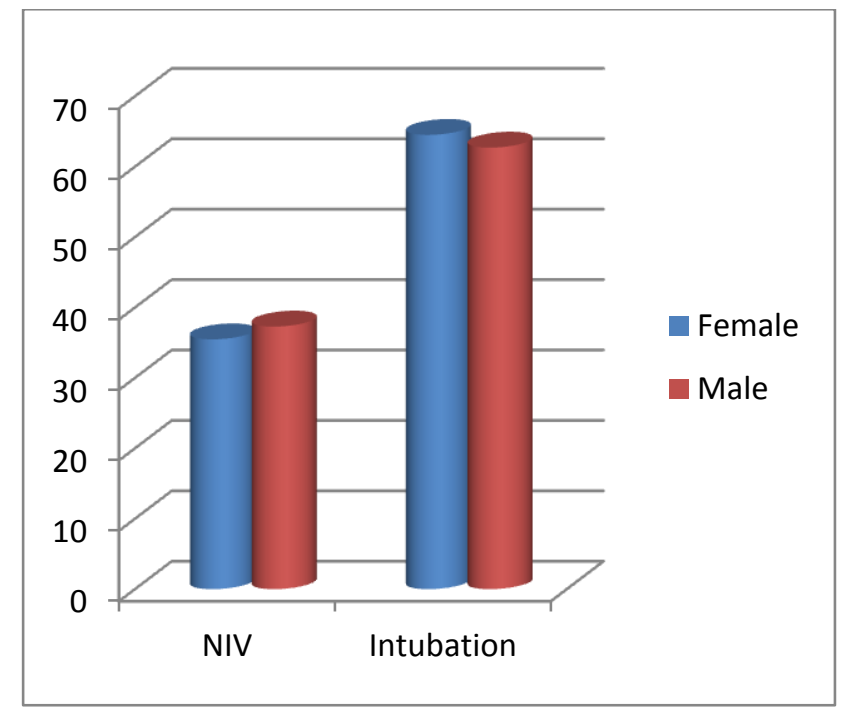

Figure 5: Type of ventilation required among male and female

Distribution of most prevalent diagnosis: Table shows most common diagnosis was COPD exacerbation $(22 \%)$.

Table 6: Diagnosis distribution among study subjects

\begin{tabular}{|c|c|c|}
\hline Diagnosis & Frequency & Percent \\
\hline $\begin{array}{l}\text { Acute Heart Failure without } \\
\text { pulmonary edema }\end{array}$ & 5 & $5.00 \%$ \\
\hline Acute pulmonary edema & 1 & $1.00 \%$ \\
\hline ARDS & 5 & $5.00 \%$ \\
\hline Carcinoma breast & 1 & $1.00 \%$ \\
\hline Carcinoma Larynx & 1 & $1.00 \%$ \\
\hline Cardiac arrest( post resuscitation) & 3 & $3.00 \%$ \\
\hline Cardiogenic shock & 5 & $5.00 \%$ \\
\hline Chronic Liver Disease & 1 & $1.00 \%$ \\
\hline Chronic Kidney Disease & 12 & $12.00 \%$ \\
\hline COPD exacerbation & 22 & $22.00 \%$ \\
\hline Cor pulmonale & 1 & $1.00 \%$ \\
\hline Cerebrocasvular accident & 4 & $4.00 \%$ \\
\hline Cerebral venous sinus thrombosis & 1 & $1.00 \%$ \\
\hline Diabetic Ketoacidosis & 3 & $3.00 \%$ \\
\hline Guillain-Barre $\square$ syndrome & 1 & $1.00 \%$ \\
\hline Head injury & 4 & $4.00 \%$ \\
\hline Pulmonary Tuberculosis & 2 & $2.00 \%$ \\
\hline Intracranial hemorrhage & 5 & $5.00 \%$ \\
\hline Generalised Tonic Clonic Seizure & 2 & $1.00 \%$ \\
\hline Lower Respiratory Tract Infection & 4 & $4.00 \%$ \\
\hline Meningitis & 2 & $2.00 \%$ \\
\hline Myocardial infarction & 5 & $5.00 \%$ \\
\hline Phenol poisoning & 1 & $1.00 \%$ \\
\hline Pulmonary embolism & 2 & $2.00 \%$ \\
\hline Septic shock & 6 & $6.00 \%$ \\
\hline Tetanus & 1 & $1.00 \%$ \\
\hline Polytrauma & 1 & $1.00 \%$ \\
\hline Total & 100 & $100.00 \%$ \\
\hline
\end{tabular}


Distribution of mode of NIV and invasive ventilation used among study subjects:

In this study, out of the patients who were invasively ventilated, $63 \%$ were on volume assist mode and $4 \%$ on pressure control mode. Out of 33 patients kept on NIV 11 patients were on CPAP mode and rest 22 were kept on PSV+CPAP mode.

Table 7: Mode used for ventilation

\begin{tabular}{lcc}
\hline Mode used & Frequency & Percent \\
\hline CPAP & 11 & $11.00 \%$ \\
PSV+CPAP & 22 & 22 \\
Pressure Control & 4 & $4.00 \%$ \\
Volume Assist Mode & 63 & $63.00 \%$ \\
Total & 100 & $100.00 \%$ \\
\hline
\end{tabular}

\section{Modes Used}

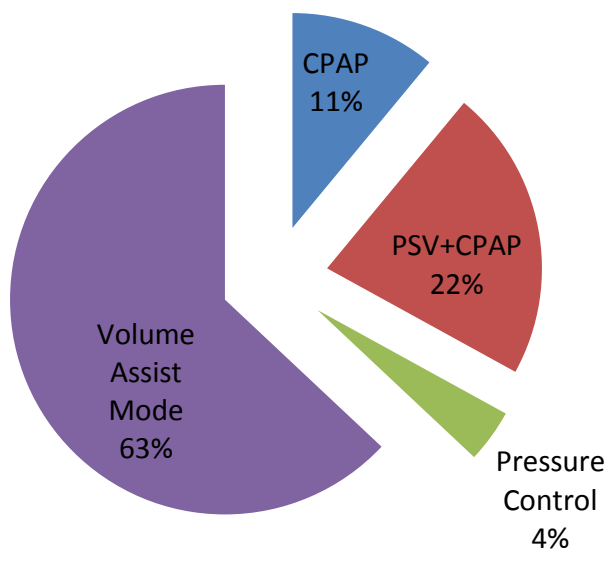

Figure 6: Mode used for ventilation

Distribution of ABG of patients with mechanical ventilation

It was observed that $42 \%$ subjects had respiratory acidosis, 29\% had metabolic acidosis and 13\% had normal findings on ABG analysis.

Table 8: Distribution of ABG findings among study subjects

\begin{tabular}{lcc}
\hline ABG & Frequency & Percent \\
\hline Respiratory acidosis & 42 & $42.00 \%$ \\
Metabolic acidosis & 29 & $29.00 \%$ \\
Normal & 13 & $13.00 \%$ \\
Respiratory alkalosis & 10 & $10.00 \%$ \\
Metabolic alkalosis & 6 & $6.00 \%$ \\
Total & 100 & $100.00 \%$ \\
\hline
\end{tabular}

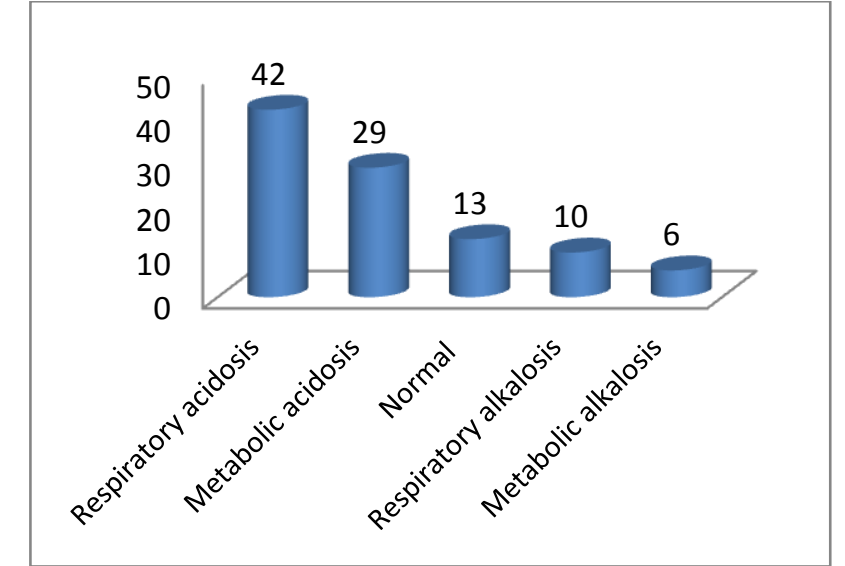

Figure 7: Distribution of $\mathrm{ABG}$ findings among study subjects.

Distribution of type of ventilation required among different ABG findings

In intubation group metabolic acidosis was found in majority of subjects while in NIV group respiratory acidosis was most commonly seen. 10 study subjects who required both NIV and invasive mode of ventilation were excluded from this table.

Table 9: ABG finding in NIV and Intubation group of study subjects

\begin{tabular}{|c|c|c|c|}
\hline \multirow[b]{2}{*}{$\mathrm{ABG}$} & \multicolumn{2}{|c|}{ Ventilation } & \multirow[b]{2}{*}{ Total } \\
\hline & NIV & Intubation & \\
\hline Metabolic acidosis & $4(15.38 \%)$ & $22(84.62 \%)$ & 26 \\
\hline Metabolic alkalosis & 0 & $6(100.00 \%)$ & 6 \\
\hline Normal & $1(7.69 \%)$ & $12(92.31 \%)$ & 13 \\
\hline Respiratory acidosis & $24(64.86 \%)$ & $13(35.14 \%)$ & 37 \\
\hline $\begin{array}{l}\text { Respiratory } \\
\text { alkalosis }\end{array}$ & $4(50.00 \%)$ & $4(50.00 \%)$ & 8 \\
\hline Total & $33(36.67 \%)$ & $57(63.33 \%)$ & 90 \\
\hline
\end{tabular}

12 Patients with normal ABG were kept on invasive mode of ventilation because their GCS was less than 8 and they couldn't protect their airway from aspiration, tongue fall etc. There were no ventilatory problems found in those subjects.

The diagnosis for these patients were as follows Table 10: Diagnosis of patients with GCS $<8$ and normal ABG

\begin{tabular}{lcc}
\hline $\begin{array}{l}\text { Serial } \\
\text { number }\end{array}$ & DIAGNOSIS & $\begin{array}{c}\text { Number of } \\
\text { patients }\end{array}$ \\
\hline 1) & CVA with HTN & 2 \\
2) & Meningitis & 2 \\
$3)$ & Hypertensive Bleed & 3 \\
$4)$ & Myocardial Infarction & 3 \\
\hline 5$)$ & CVST & 1 \\
$6)$ & Cardiogenic shock with & 1
\end{tabular}

IHD 
Distribution of Glassgow coma scale among study subjects:

In our study it was found that out off 33 subjects who were put on NIV the GCS score was 15/15 $(100 \%)$. However, among 57 subjects who were intubated, 16 subjects had GCS of less than 15 and 41 subjects had GCS 15 (intubated due to abnormal ventilation.). 10 patients with NIV failure and later intubated had GCS of $15 / 15$ on initial evaluation. From the following table we observed that subjects with lower GCS on presentation required invasive ventilator support.

Table 11: Mode of ventilation required according to GCS.

\begin{tabular}{lccc}
\hline \multicolumn{4}{c}{ Ventilation } \\
\hline GCS & NIV & Intubation & Total \\
$<15$ & 0 & $16(100.00 \%)$ & 16 \\
15 & $33(44.59 \%)$ & $41(55.41 \%)$ & 74 \\
Total & $33(36.67 \%)$ & $57(63.33 \%)$ & 90 \\
\hline
\end{tabular}

\section{Distribution of SpO2 among study subjects}

We have found that the oxygen saturation of the peripheral blood $\left(\mathrm{SpO}_{2}\right)$ out of 80 subjects who were not maintaining saturation on high flow oxygen at presentation, 33 subjects were kept on NIV and 47 subjects were intubated. Also 10 subjects even with normal $\mathrm{SpO}_{2}$ required intubation due to other indications. 10 subjects who were put on NIV followed by intubation were not included in this table.

Table 12: Mode of ventilation required depending on $\mathrm{SpO} 2$.

\begin{tabular}{lccc}
\hline \multirow{2}{*}{ SpO2 } & \multicolumn{2}{c}{ Ventilation } & \\
\cline { 2 - 3 } Decreased & $33(41.25 \%)$ & $47(58.75 \%)$ & Total \\
Normal & 0 & $10(100.00 \%)$ & 10 \\
Total & $33(36.67 \%)$ & $57(63.33 \%)$ & 90 \\
\hline
\end{tabular}

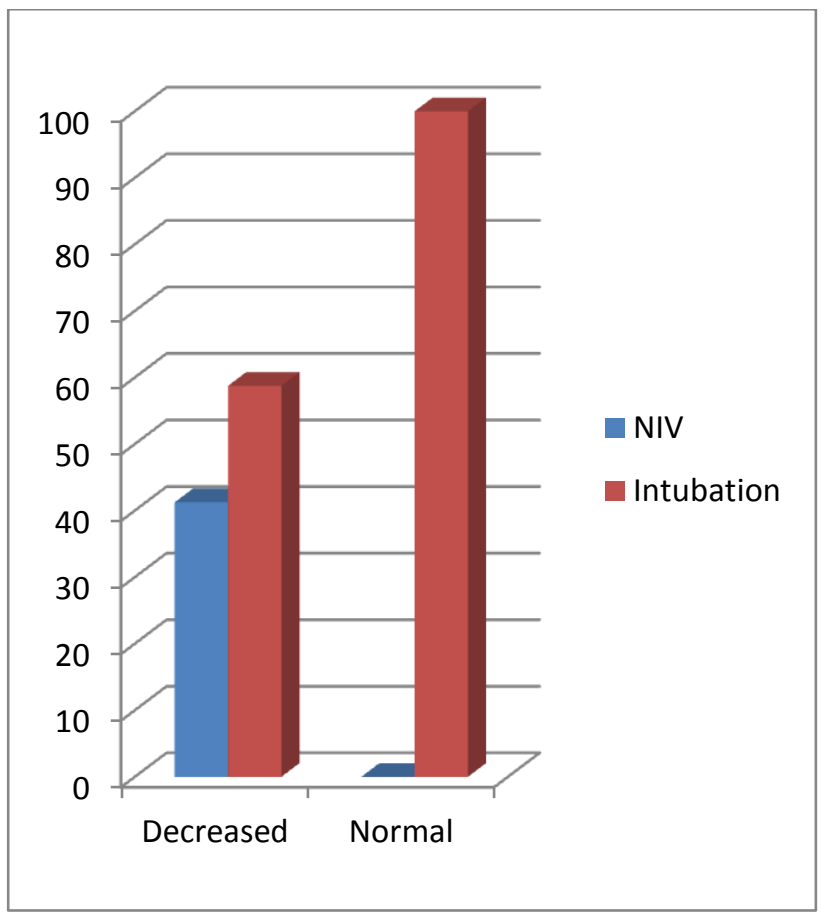

Figure 8: Mode of ventilation required depending on $\mathrm{SpO} 2$.

\section{Distribution of variables of general examination among study subjects}

The general examination variables were tabulated and compared amongst the intubated subjects versus subjects on NIV. Median for systolic BP in NIV group was 140 while that for intubation group was 100. Median for diastolic BP in NIV group was 90 and those in intubation group were 63 .

Median Respiratory rate for NIV group was 38 and that for intubation group is 32 . We found that out of various parameters assessed among NIV and intubation group Systolic BP, Diastolic BP and Respiratory rate showed significant difference in mean values $(\mathrm{p}<0.05)$. Temperature, pulse and spo2 did not show any significant variation in NIV and intubation group.

Table 13: Distribution of median value of variables (of general examination) in NIV and intubation group

\begin{tabular}{|c|c|c|c|}
\hline \multirow[t]{2}{*}{ Variables } & NIV & Intubation & $\mathbf{P}$ \\
\hline & Median(Range) & Median(Range) & value \\
\hline Temperature & $99(98-102)$ & $99(98-104)$ & 0.9285 \\
\hline Systolic BP, & $140(92-182)$ & $100(60-210)$ & 0.006 \\
\hline Diastolic BP, & $90(56-120)$ & $63(30-130)$ & 0.01 \\
\hline $\begin{array}{l}\text { Respiratory } \\
\text { rate }\end{array}$ & $38(28-49)$ & $32(10-52)$ & 0.0032 \\
\hline Pulse & $114(62-137)$ & $119(43-157)$ & 0.457 \\
\hline Spo2 & $84(60-92)$ & $84(30-98)$ & 0.4206 \\
\hline
\end{tabular}




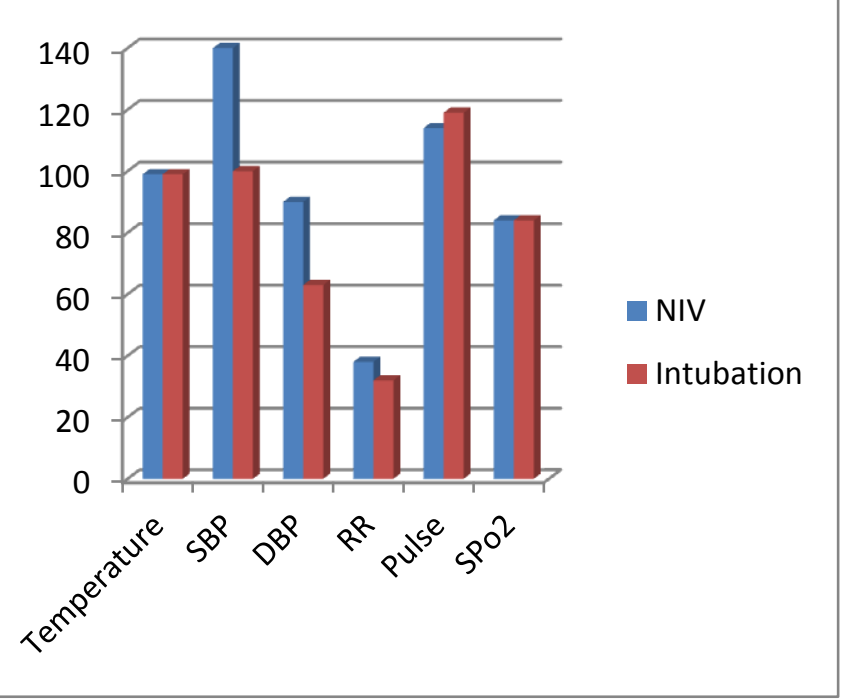

Figure 9: Distribution of median value of variables (of general examination) in NIV and intubation group.

\section{Distribution of Raised Respiratory Rate}

The cutoff for raised RR is taken as 25 in our study. We observed patients who required mechanical ventilation with $R R>25,42$ were kept on NIV and 44 required invasive mode of ventilation.

\section{Discussion}

This observational study is conducted with 100 patients aimed at evaluating the clinical profile of patients intubated and those on NIV in ED.

\section{Mode of Ventilation}

In this study we have found that out of 100 patients who required ventilation; $57 \%$ were invasively ventilated, 33\% were on NIV and those who required intubation after NIV due to NIV failure were $10 \%$. This is similar to a study by Venkatram, et $\mathrm{al}^{[\mathbf{1}]}$ In which $59 \%$ of the patients were subjected to IMV, 35.6\% subjected to NIMV and $5.45 \%$ of the patients demonstrated NIMV failure and needed endotracheal intubation. Similar study was conducted by Mohamad A Zamzam, et al which included 130 patients subjected to Mechanical Ventilation (MV); divided into three groups according to the type of MV: Group A: Invasive Mechanical Ventilation: 52 patients (40\%), Group B: Non Invasive Mechanical Ventilation : 66 patients $(50.77 \%)$ and Group C: NIMV failure that needed IMV: 12 patients $(9.23 \%)^{[2]}$

\section{Distribution according to Age}

In the present study Maximum 31\% subjects were in age group of $61-70 \mathrm{yrs}$ followed by $21 \%$ subjects in $51-60 y r s \quad 13 \%$ subjects in 41-50yrs and $12 \%$ subjects in 71-80yrs. Mean age of study subjects was $57.37+16.42$. This was similar to the study conducted by Mohamed A. Zamzama, et al that demonstrated the mean age of all the studied patients was $58.47 \pm 8.2$ years, $^{\text {, }}{ }^{[2]}$.

Also it was found that there was increased requirement of invasive mechanical ventilation with increase in age.

Our study was in agreement with a study done by Venkatram et al., Paolo et al. and Antonelli et $\mathrm{al}^{[1,3,4]}$, the need for IMV in the older age.

\section{Gender Distribution}

In present study the subjects were predominantly males $(67 \%)$ than females $(33 \%)$ with gender-wise distribution of study subjects. M:F was 2.03:1. Male subjects required mechanical ventilation more than female subjects. However the percentage of males requiring intubation was $62.71 \%$ and male subjects requiring NIV was $37.29 \%$. On the other hand females requiring intubation were $64.52 \%$ and female subjects requiring NIV were $35.48 \%$. There was no significant difference in mode of ventilation (invasive or non invasive) required for male and female subjects $(\mathrm{p}=0.951)$.

This was in agreement with studies by Esteban et al. ${ }^{[5]}$ and Kubler et al. ${ }^{[6]}$ which showed that men account for more than half of the patients receiving mechanical ventilation in ICU. They explained this by the commonest etiology of respiratory failure and so-often MV was COPD which is more prevalent in males than females.

\section{Distribution of diagnosis requiring mechanical} ventiltation

In our study we found that most prevalent diagnosis requiring mechanical ventilation was acute exacerbation of chronic obstructive pulmonary disease $(22 \%)$, followed by Chronic Kidney disease $(11 \%)$, and septic shock (6\%).

Kubler et al ${ }^{[6]}$ showed the commonest etiology of respiratory failure leading to IMV and NIMV was 
COPD (14\% and $44 \%$ respectively) followed by ARDS, pneumonia, cardiogenic pulmonary edema and others in IMV.

\section{Distribution of mode of mechanical ventilation used in study subjects}

In this study, out of the patients who were invasively ventilated, $63 \%$ were on volume assist mode and $4 \%$ on pressure control mode. Out of 33 patients kept on NIV 11 patients were on CPAP mode and rest 22 were kept on PSV+CPAP mode.

This differs from the study by Mohamed A Zamzam, et al where the most common initial mode of MV in group A was IPPV (intermittent positive pressure ventilation;76.9\%) followed by SIMV (synchronised intermittent mandatory ventilation; 23.1\%). In NIMV, the modes were $\operatorname{BiPAP}(84.9 \%)$ followed by CPAP $(15.2 \%)$.

\section{Distribution of ABG findings in study group}

It was observed that $42 \%$ subjects had respiratory acidosis, 29\% had metabolic acidosis and 13\% had normal findings on $\mathrm{ABG}$ analysis. In intubation group metabolic acidosis was found in majority of subjects while in NIV group respiratory acidosis was most commonly seen. There were 12 Patients with normal ABG who were kept on invasive ventilation because they were intubated with indication of GCS <8. They had no ventilatory abnormality.

This differs from studies by Confalonieri et $\mathrm{al}^{\left[{ }^{[7]}\right.}$,Massimo et al. $^{[8]}$ and Shirakabe et al ${ }^{[9]}$ that showed that lower $\mathrm{pH}$ increases the risk of IMV.

\section{Distribution of GCS on presentation}

In our study it was found that out off 33 subjects who were put on NIV the GCS score was 15/15. However, among 57 subjects who were intubated, 16 subjects had GCS of less than 15 and 41 subjects had GCS 15.

This differs from the study by Duncan $\mathrm{R}$ et al ${ }^{[10]}$ who did an observational study on patients presenting with decreased consciousness admitted in ED. They concluded that it can be safe to observe poisoned patients with decreased consciousness, even if they have a GCS of 8 or less, in the ED.

\section{Distribution of $\mathrm{SpO}_{2}$ among study subjects}

In present study we found that out of 80 subjects who presented with decreased $\mathrm{SpO} 2$ on room air and not maintained $\mathrm{SpO}_{2}$ after giving high flow oxygen at presentation, 33 subjects were kept on NIV and 47 subjects were intubated. Also 10 subjects with normal $\mathrm{SpO}_{2}$ were intubated due to other reasons like low GCS.

This differed from the the study by Spada et al. ${ }^{[11]}$ who analyzed the $\mathrm{SpO}_{2}$ and demonstrated that greater $\mathrm{SpO}_{2}$ was associated with NIV success.

Distribution of General evamination variables among study subjects

In present study, the general examination variables were tabulated and amongst the intubated subjects versus subjects on NIV. We found that out of various parameters assessed among NIV and intubation group Systolic BP, Diastolic BP and Respiratory rate showed significant difference in mean values $(\mathrm{p}<0.05)$.

The cutoff for raised RR is taken as 25 in our study. We observed patients who required mechanical ventilation with $R R>25,42$ were kept on NIV and 44 required invasive mode of ventilation.

In the study by Chalmers JD, Singanayagam A, et $\mathrm{al}^{[12]}$ demonstrated that on admission blood pressure can predict 30 day mortality and need for mechanical ventilation and/or inotropic support in patients admitted with community acquired pneumonia. They concluded that with reducing systolic blood pressure, diastolic blood pressure, mean arterial pressure and pulse pressure there was increasing 30 day mortality and need for mechanical ventilation.

Another study done by Ivete Alonso Bredda Saad, Juliana Nalin de Souza Passarini, et al with aim to evaluate predictors of success or failure of NIV in an emergency department, demonstrated that respiratory rate above 25 may be associated with progression to invasive ventilation. ${ }^{[13]}$

\section{Conclusion}

This observational study concludes that the invasive mode of mechanical ventilation is more common in our ED. Amongst the demographic features, we 
found that as the age increases chances of invasive mode of mechanical ventilation also increases. However gender does not affect the choice of mode of mechanical ventilation.

The most common mode of invasive ventilation used is volume assist mode and for NIV mode 22 patients were on CPAP + PSV mode and 11 were on CPAP mode.

The most prevalent diagnosis for mechanical ventilation is COPD exacerbation and respiratory acidosis on $\mathrm{ABG}$. Low $\mathrm{SpO} 2$, increased respiratory rate, low systolic and diastolic BP and low GCS on presentation were more associated with invasive mode of ventilation and can help to predict the need for invasive mode mechanical ventilation.

\section{References}

1. S. Venkatram, S. Rachmale, B. Kanna, et al, Non-invasive positive pressure ventilation compared to invasive mechanical ventilation among patients with COPD exacerbations in an inner city MICU - predictors of NPPV use, Internet J. Pulm.Med. 12 (2009) 1.

2. A. Zamzama, Amal A. Abd El Aziza, et al. Study of the characteristics and outcomes of patients on mechanical ventilation in the intensive care unit of EL-Mahalla Chest Hospital. Egyptian journal of chest disease and tuberculosis. Volume 64(2015);Pages 693-70.

3. S. Paolo, et al. Effect of noninvasive mechanical ventilation in elderly patients with hypercapnic acute or chronic respiratory failure and a do-not-intubate order. Int. J. Chron. Obstructive Pulm. Dis., 3 (4) (2008), pp. 797-801.

4. M. Antonelli, G. Conti, M.L. Moro et al. Predictors of failure of noninvasive positive pressure ventilation in patients with acute hypoxemic respiratory failure: a multicenter study. Intensive Care Med., 27 (2001), pp. 1718-1728.

5. A. Esteban, A.N. Antonius, F.R. Fernando et al. Characteristics and outcome in adult patients receiving mechanical ventilation A28 day study JAMA, 287 (3) (2002), pp. 345355.

6. A. Kubler, D. Macjejewski, B. Adamik et al. Mechanical ventilation in ICUS in Poland. A multi-center point-prevalence study. Med. Sci. Monit., 19 (2013), pp. 424-429

7. M. Confalonieri, G. Garuti, M.S. Cattaruzza, et al, A chart offailure risk for noninvasive ventilation in patients with COPD exacerbation, Eur. Respir.J.25(2005) 348-355.

8. A. Massimo, C. Giorgio, R. Monica.

Comparison of noninvasive positive pressure ventilation and conventional mechanical ventilation in patients with acute respiratory failure. N. Engl. J. Med., 339 (1998), pp. 429435.

9. A. Shirakabe, N. Hata, S. Yokoyama, et al.Predicting the success of noninvasive positive pressure ventilation in emergency room for patients with acute heart failure. J. Cardiol., 57 (1) (2011), pp. 107-114.

10. Russell Duncan, Shobhan Thakore, et al. Decreased Glasgow Coma Scale Score Does Not Mandate Endotracheal Intubation in the Emergency Department. The Journal of Emergency Medicine. Volume 37, Issue 4, November 2009, Pages 451-455.

11. Carol Spada, Rikesh Gandhi, et al. Oxygen saturation/fraction of inspired oxygen ratio is a simple predictor of noninvasive positive pressure ventilation failure in critically ill patients. Journal of Critical Care.Volume 26, Issue 5, October 2011, Pages 510-51.

12. Chalmers JD, Singanayagam A, Hill AT, et al. Systolic blood pressure is superior to other haemodynamic predictors of outcome in community acquired pneumonia. Thorax 2008;63:698-702.

13. Juliana Nalin de Souza Passarini, Carolina Kosour, et al. Noninvasive ventilation in emergency: Predictors of success or failure in cases of acute pulmonary edema and the exacerbation COPD. European Respiratory Journal 2012 40: P1192. 